\title{
Early identification of peripheral neuropathy based on sudomotor dysfunction in Mexican patients with type 2 diabetes
}

\author{
Angelica Carbajal-Ramírez ${ }^{1 *}$, Julián A. Hernández-Domínguez², Mario A. Molina-Ayala³, \\ María Magdalena Rojas-Uribe ${ }^{2}$ and Adolfo Chávez-Negrete ${ }^{3}$
}

\begin{abstract}
Background: Type 2 Diabetes in Mexico has a high prevalence, 16-87\% of patients may experience peripheral neuropathy. Early detection can prevent or halt its progression. The performance of Sudoscan in detecting neuropathy was compared to the Michigan Neuropathy Screening Instrument (MNSI). The aim was to identificate small fibers neuropathy.

Methods: Patients type 2 diabetes received both MNSI and sudomotor function assessment through measurement of electrochemical skin conductance (ESC) in the hands and feet.

Results: Two hundred twenty-one patients with neuropathy according to MNSI B had lower hands and feet ESC, regardless of diabetes duration. Among the 170 patients who had had diabetes for at least 5 years, 76 of them with normal MNSI B had abnormal hands or feet ESC; this was also the case in 28 out of 51 patients with diabetes than 5 or more years. In contrast, only 5 patients in the first group and 1 in the second group had abnormal MNSI B with normal ESC. Using MNSI B as a reference, abnormal hands or feet ESC $(<60 \mu$ S and $70 \mu S$ respectively $)$ had a sensitivity of $97 \%$, positive predictive value of $87 \%$ to detect neuropathy in patients with longer diabetes duration. The group with shorter diabetes duration, the sensitivity of abnormal hands or feet ESC to detect neuropathy was 91\% while the positive predictive value was $88 \%$.
\end{abstract}

Conclusions: The Sudoscan device, which does not require any preparation, is noninvasive, easy and rapid to perform, can be useful in the early diagnosis peripheral neuropathy in type 2 diabetic.

Keywords: MNSI, Electrochemical skin conductances, Small fiber neuropathies, Diabetic neuropathy

\section{Background}

Type 2 diabetes is now recognized as an immense and growing public health challenge worldwide, affecting about 382 million adults in 2014 and predicted to rise to 471 million by $2035[1,2]$. Worryingly, in Mexico the prevalence is between $7.34 \%$ (2006 estimates) and 9.2\%. According the ENSANUT survey in 2012 [3], 1.4\% of diabetic patients received an amputation, underscoring the

\footnotetext{
* Correspondence: angyc@prodigy.net.mx

${ }^{1}$ Centro Médico Nacional Siglo XXI, Instituto Mexicano del Seguro Social (IMSS), Av. Cuauhtemoc 330, 06720 Mexico City, Mexico

Full list of author information is available at the end of the article
}

significant overall economic cost impact of the disease $\$ 778,427,475$ US dollars in 2011 [4].

The prevalence of diabetic peripheral neuropathy (DPN) varies according to different authors and instruments used for diagnosis; it is estimated to be between 16 and $87 \%$. At time of diagnosis of type 2 diabetes, $7.5 \%$ of patients already have neuropathy [5-7] DPN has an annual incidence of $2 \%$ and is the most common neuropathy in industrialized countries [8]. Additionally DPN is a risk factor for complications such as diabetic foot - one out of every 5 patients presents with diabetic foot. In Mexico, 20\% require foot amputation and 30\% require a second amputation in the next 12 months [9].

(c) The Author(s). 2019 Open Access This article is distributed under the terms of the Creative Commons Attribution 4.0 International License (http://creativecommons.org/licenses/by/4.0/), which permits unrestricted use, distribution, and 
Table 1 Characteristics of the study population

\begin{tabular}{|c|c|c|c|}
\hline & Diabetes since Less than 5 years & Diabetes since 5 years or more & $p$ value $^{*}$ \\
\hline$n$ & 170 & 51 & \\
\hline Age (yrs) & $58.6 \pm 12.6$ & $63.8 \pm 11.8$ & 0.0095 \\
\hline Gender, n (\%) & & & 0.364 \\
\hline Male & $55(32)$ & $20(39)$ & \\
\hline Female & $115(68)$ & $31(61)$ & \\
\hline $\mathrm{BMI}\left(\mathrm{kg} / \mathrm{m}^{2}\right)$ & $28.8 \pm 6.2$ & $27.2 \pm 3.9$ & 0.0297 \\
\hline Abnormal Michigan part B, n (\%) & $58(34)$ & $29(57)$ & 0.0035 \\
\hline Abnormal Feet ESC, $n(\%)^{a}$ & $121(71)$ & $44(86)$ & 0.1116 \\
\hline Abnormal Hands ESC, n (\%) ${ }^{\text {a }}$ & $51(30)$ & $33(65)$ & $<0.0001$ \\
\hline Abnormal Hands or Feet ESC, n (\%) & $129(76)$ & $43(84)$ & 0.2036 \\
\hline Feet ESC $(\mu S)$ & $58.6 \pm 12.6$ & $47.9 \pm 20.2$ & 0.0009 \\
\hline Hands ESC $(\mu S)$ & $64.5 \pm 16.3$ & $48.5 \pm 21.5$ & $<0.0001$ \\
\hline
\end{tabular}

$¥ p$ value of Student test for means and $\mathrm{chi}^{2}$ test for percentages

${ }^{a}$ Abnormal feet ESC is defined as feet ESC $<70 \mu \mathrm{S}$ and $60 \mu \mathrm{S}$ for hands

Diabetic neuropathy encompasses a complex group of heterogeneous clinical manifestations, the most common being sensory-motor $[10,11]$. DPN's effects on autonomic function remain less investigated [12]. Studies suggest that the prevalence of autonomic cardiac neuropathy in diabetes ranges from $2.5 \%$ to as high as $90 \%$, depending on the identifying criteria, and is often underdiagnosed $[13,14]$.

The clinical diagnosis of neuropathy using the Michigan Neuropathy Screening Instrument (MNSI) parts A (symptoms) and B (physical exam) is useful for its high sensitivity and specificity [15]. The consensus statement of the American Diabetes Association (ADA), the American Academy of Neurology (ANA) and Latin American Diabetes Association (ALAD) includes assessing sudomotor function's role in the early diagnosis of autonomic neuropathy in diabetes $[16,17]$. Sudoscan is a noninvasive, quick, easy, and reproducible method for the quantitative assessment of sudomotor function, through local measurements of electrochemical skin conductances [18-25].

We compared the results of Sudoscan and MNSI parts A and $B$ for the identification of peripheral neuropathy in patients with type 2 diabetes, divided in two groups according to diabetes duration: less than 5 years and 5 years or more.

\section{Methods}

The study was conducted at the Specialty Hospital of the National Medical Center Siglo XXI from March 2015 through February 2016, and was approved by the
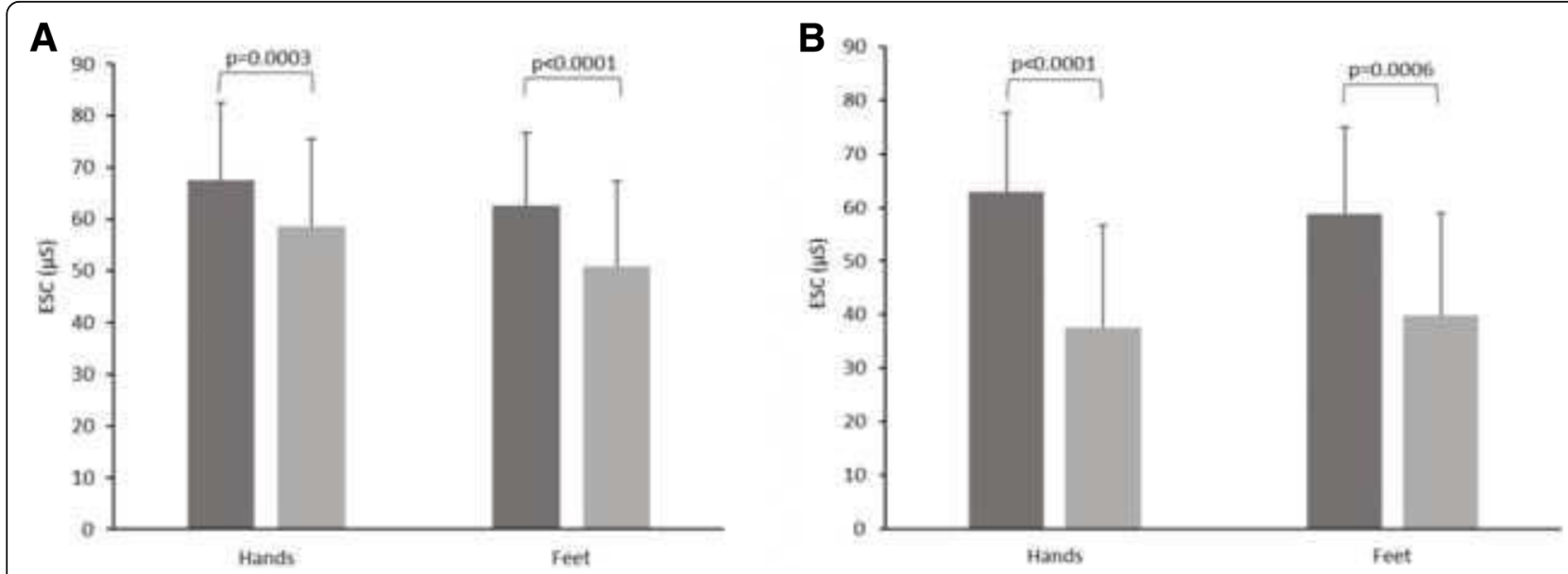

Fig. 1 a. Distribution of hands and feet ESC according to MNSI (B) in type 2 diabetes patients since less than 5 years. In normal MNSI (B) group (left bar) mean ESC was $67.5 \pm 15.0 \mu \mathrm{S}$ for hands and $62.6 \pm 14.1 \mu \mathrm{S}$ for feet. In abnormal MNSI group (B) (right bar) it was $58.6 \pm 17.1 \mu \mathrm{S}$ and $50.9 \pm 16.4 \mu \mathrm{S}$ respectively. b. Distribution of hands and feet ESC according to MNSI (B) in type 2 diabetes patients since at least 5 years. In normal MNSI (B) group (left bar) mean ESC was $62.9 \pm 14.8 \mu \mathrm{S}$ for hands and $58.7 \pm 16.3 \mu \mathrm{S}$ for feet. In abnormal MNSI group (B) (right bar) it was $37.5 \pm$ $19.3 \mu \mathrm{S}$ and $39.8 \pm 19.1 \mu \mathrm{S}$ respectively 
Table 2 Means and median of SUDOSCAN measures according to MNSI(B) in diabetic patients $<5$ years

\begin{tabular}{|c|c|c|c|c|c|c|}
\hline & \multicolumn{2}{|c|}{ Normal Michigan B $(n=112)$} & \multicolumn{2}{|c|}{ Abnormal Michigan B $(n=58)$} & \multirow{2}{*}{$\begin{array}{l}p \text { value } \\
\text { for } \\
\text { means }\end{array}$} & \multirow{2}{*}{$\begin{array}{l}p \text { value } \\
\text { for } \\
\text { median }\end{array}$} \\
\hline & Mean \pm STD & Median (Q1-Q3) & Mean \pm STD & Median (Q1-Q3) & & \\
\hline Hands ESC $(\mu S)$ & $67.5 \pm 15.0$ & $72(60-78)$ & $58.6 \pm 17.1$ & $61(49-71)$ & 0.0003 & 0.0008 \\
\hline Feet ESC $(\mu S)$ & $62.6 \pm 14.1$ & $66(55-73)$ & $50.9 \pm 16.4$ & $53(40-63)$ & $<0.0001$ & $<0.0001$ \\
\hline
\end{tabular}

$P$ value of Wilcoxon test for means and $x^{2}$ for medians

local research committee. Each patient signed a consent letter. Male and female adults aged 18 to 80 years, with or without symptoms of neuropathy, were enrolled. Two groups of patients were defined: those less than 5 years and those at least 5 years or more from diagnosis of type 2 diabetes according to ADA criteria. Patients who had undergone amputation of a limb were excluded. Medical history, weight, body mass index, and medications were recorded. We used the MNSI questionnaire to record patient responses regarding neuropathy and symptoms. For MNSI part B we performed a physical examination that included evaluation of skin changes, infection, muscle stretch reflexes, vibration sensation using a 128 $\mathrm{Hz}$ "diapason" on both feet, and pressure perception using a $10 \mathrm{~g}$ monofilament (Semmes-Weinstein monofilament Examination).

The evaluation of sudomotor function was measured with the Sudoscan medical device, consisting of a set of two electrodes for feet and hands connected to a computer. The duration of the test is $3 \mathrm{~min}$ on average, in which 4 combinations of 15 different low-voltage stimuli are applied. The patient does not require any preparation, and has only to place their palms and soles on the stainless-steel electrodes and remain for the test duration. The device measures the conductance generated in response to the electrical stimulus, which is expressed in micro Siemens for both the right and left side. It is a method based on stimulation of sweat glands by the low-level voltage, allowing evidence of sweat dysfunction not detectable under physiological conditions. No subject preparation is required for this test. Performance and accuracy of the method has been evaluated in numerous clinical studies [18-25].

Statistical analyses. Results for quantitative variables are shown as means $\pm \mathrm{SD}$. Quantitative variables were globally compared using ANOVA analysis. As a rule, a $p$-value $<0.05$ was regarded as statistically significant. Performance of measurement of sudomotor dysfunction was assessed using Receiver Operating Curve (ROC) with calculation of the Area under the Curve (AUC). The data management and statistical analysis were done using SAS version 9.4 and $R$ version 2.13.1 [26].

\section{Results}

Of the 221 patients involved in the study, 51 had diabetes duration of 5 years o more. In the group patients were older, had lower BMI, and had more severe neuropathy according to MNSI B - they also had lower hands and feet ESC (Table 1).

In both groups, patients with neuropathy according to MNSI B had lower hands and feet conductances (Fig. 1a and b). In both groups, more patients had abnormal ESC as compared to abnormal MNSI B (Tables 2 and 3).

In particular, among the 170 patients with 5 or more years diabetes duration, 76 patients with normal MNSI $\mathrm{B}$ had abnormal hands or feet ESC, while this was true for 28 out of 51 in the other group. In contrast only 5 patients in the first group and 1 in the second group had abnormal MNSI B with normal ESC. Using MNSI B as a reference, hands or feet abnormal ESC $(<60 \mu \mathrm{S}$ and 70 $\mu \mathrm{S}$ respectively) had a sensitivity of $97 \%$ and a positive predictive value (PPV) of $87 \%$ to detect neuropathy in patients with longer diabetes duration (Fig. 2). In patients with diabetes duration of less than 5 years, AUC of ROC curves for hands and feet ESC were 0.66 and 0.72 respectively (Fig. 3). The sensitivity of abnormal hands or feet ESC for detection of neuropathy was $91 \%$, while the positive predictive value was $88 \%$ (Table 4).

Any subject involved in the study reported neither adverse event nor discomfort during or after Sudoscan measurement.

\section{Discussion}

This study demonstrated that i) hands and feet ESC decreased with diabetes duration; ii) patients with peripheral neuropathy according to MNSI B had lower hands

Table 3 Means and median of SUDOSCAN measures according to MNSI(B) in diabetic patients $\geqq 5$ years

\begin{tabular}{|c|c|c|c|c|c|c|}
\hline & \multicolumn{2}{|c|}{ Normal MNSI B $(n=22)$} & \multicolumn{2}{|c|}{ Abnormal MNSI B $(n=29)$} & \multirow{2}{*}{$\begin{array}{l}p \text { value } \\
\text { for } \\
\text { means }\end{array}$} & \multirow{2}{*}{$\begin{array}{l}p \text { value } \\
\text { for } \\
\text { medians }\end{array}$} \\
\hline & Mean \pm STD & Median (Q1-Q3) & Mean \pm STD & Median (Q1-Q3) & & \\
\hline Hands ESC $(\mu S)$ & $62.9 \pm 14.8$ & $63(50-76)$ & $37.5 \pm 19.3$ & $33(25-49)$ & $<0.0001$ & 0.0002 \\
\hline Feet ESC ( $\mu S)$ & $58.7 \pm 16.3$ & $59(50-73)$ & $39.8 \pm 19.1$ & $42(24-53)$ & 0.0006 & 0.0035 \\
\hline
\end{tabular}

$P$ value of Wilcoxon test for means and $x^{2}$ for medians 


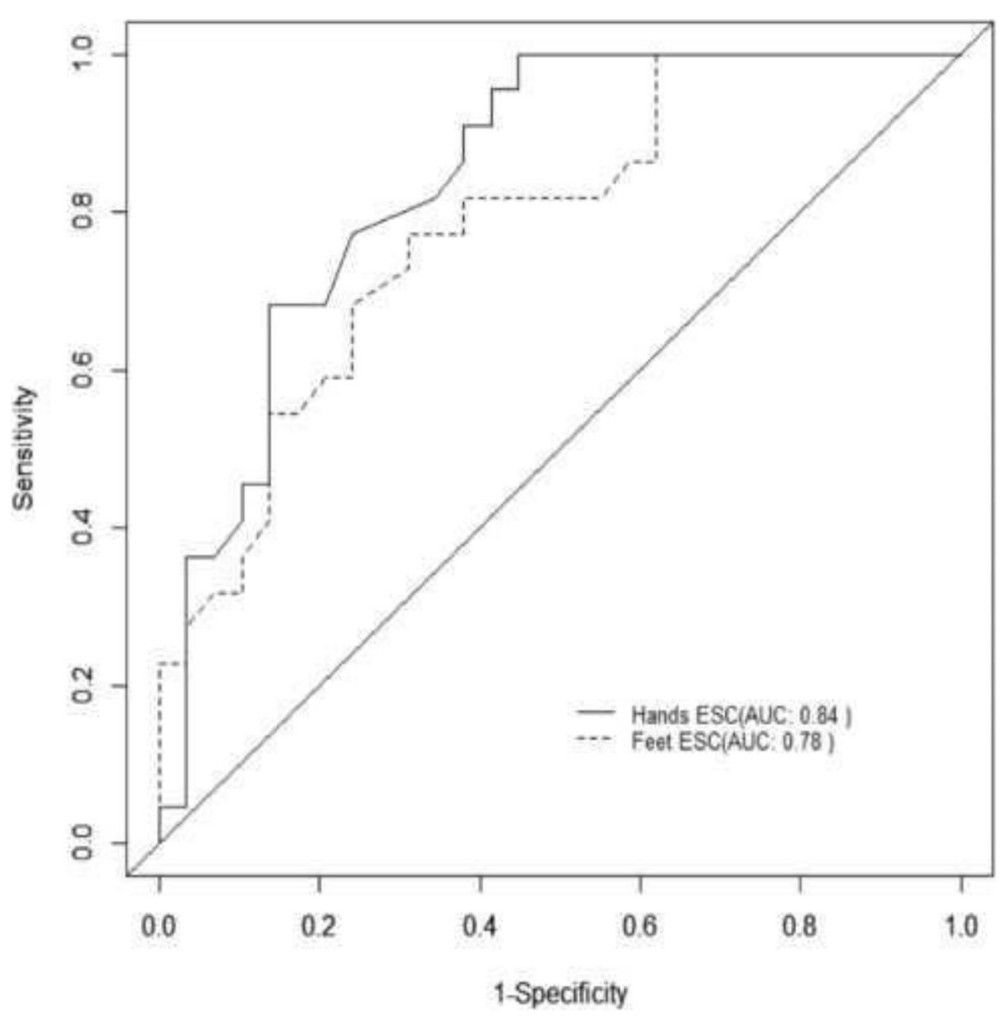

Fig. 2 ROC curve for hands and feet ESC to detect neuropathy using MNSI (B) as gold standard in diabetic patients since less than 5 years

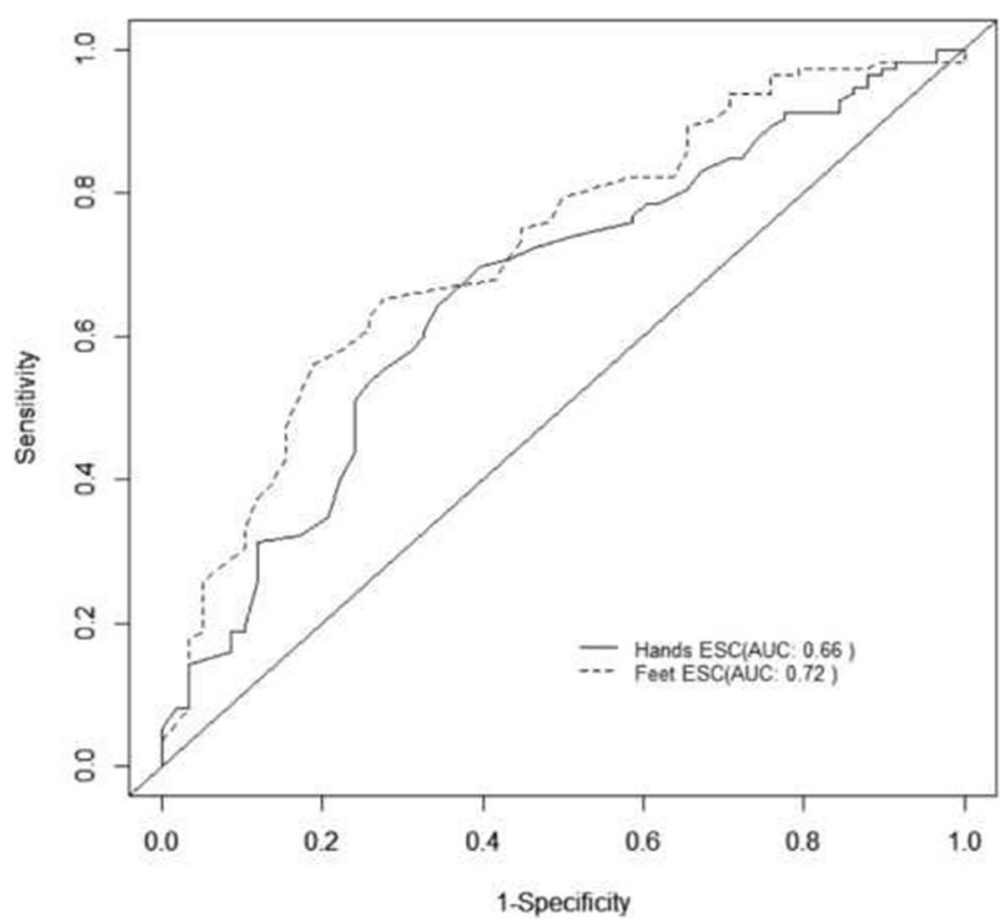

Fig. 3 ROC curve for hands and feet ESC to detect neuropathy using MNSI (B) as gold standard in diabetic patients since at least 5 or more years 
Table $4 \mathrm{Chi}^{2}$ tests between Sudoscan and MNSI

\begin{tabular}{lcl}
\hline & MNSI (B) & \\
\cline { 2 - 3 } & Normal & Abnormal \\
\hline Diabetic patients since $<5$ years & 36 & 5 \\
Hands and feet ESC both normal & 76 & 53 \\
At least one abnormal & $p c h i^{2}=0.0007$ & \\
Diabetic patients since $\geqq 5$ years & & 1 \\
Hands and feet ESC both normal & 7 & 15 \\
At least one abnormal & 28 & \\
& $p c h i^{2}=0.0058$ & \\
\hline
\end{tabular}

and feet ESC, whatever their diabetes duration; iii) more patients had abnormal hands or feet ESC as compared to abnormal MNSI B; and iv) detection of neuropathy based on assessment of sudomotor function using MNSI $\mathrm{B}$ as a reference had a high performance, with a sensitivity of $97 \%$ and PPV of $87 \%$ in patients with diabetes duration of at least 5 years - sensitivity and PPV were 91 and $88 \%$ respectively in patients with diabetes duration of less than 5 years.

MNSI B is a sensitive screening instrument for routine evaluation of peripheral neuropathy in diabetic patients, as evidenced in many clinical studies, but it is time consuming in a busy clinical setting [15].

Early identification of subjects with DPN using novel, non-invasive methods may allow for intensified treatment of blood glucose and cardiovascular risk factors in order to prevent or halt the progression of DPN. This is critically important, as neuropathy is significantly associated with patient morbidity (foot ulceration, amputations, disabling pain, etc.) and mortality [5-8]. Therefore, the development of non-invasive, rapid and sensitive measures of neuropathy has a clinically sound rationale. Changes in peripheral autonomic nervous system function are an early manifestation of distal small fiber neuropathy [13, 14] Sweat glands are innervated by sudomotor, thin, unmyelinated sympathetic C-fibers and a number of skin biopsy studies have shown a reduction in the epidermal C-nerve fibers in patients with diabetes or pre-diabetes [27]. Sudomotor dysfunction is one of the earliest detectable abnormalities in distal small fiber neuropathies [12]. Therefore, assessment of sudomotor function may be an attractive tool to evaluate peripheral small fiber neuropathy in diabetes.

The performance of Sudoscan - which allows rapid, non-invasive, objective and quantitative assessment of sudomotor function - has been evaluated in several clinical studies performed in diabetic populations, using various tests as references. Sensitivities observed in the present study are higher or comparable to sensitivities observed in patients with type 1 or 2 diabetes by Casellini et al. (78\% when compared to Neuropathy Impairment Score Lower Limb [NIS-LL] as reference); by Yajnik et al. (73\% when using Vibration Perception Threshold as reference); and by Selvarajah et al. ( $88 \%$ when compared to combination of NIS-LL and nerve conduction studies). MNSI, like the tests used in previous studies, mainly assesses large fibers, while sudomotor dysfunction measurement assesses small fibers $[18,25]$. Small fiber neuropathies can be observed earlier than large fiber neuropathy in type 2 diabetes, which can explain why in the present study more patients had abnormal ESC as compared to MNSI B [28]. This supports the relevance of this method of early detection. Meanwhile, comparable sensitivities were observed when Sudoscan was compared to methods which exclusively assess small fiber neuropathies, as observed by Lefaucheur et al., (76\% in patients with confirmed peripheral neuropathy as assessed by reference methods: laser evoked potential [LEP] and quantitative sensory test [QST]), or to methods assessing large and small fiber neuropathies by Smith et al., (77\% when compared to Utah Early Neuropathy Score [UENS]) [29, 21].

The present study has several limitations: i) patients were classified only by diabetes duration and only type 2 diabetes, ii) MNSI B was used as reference and comparator, iii) only sudomotor dysfunction assessment was used to assess small fiber neuropathy.

\section{Conclusions}

Sudoscan should be considered to be in accordance with the recommendations of the ADA and ANA because it is rapid, easy to perform, robust, does not require any preparation, noninvasive, and reproducible. The evaluation of sudomotor function with this innovative tool is useful in the early identification of neuropathy, as it is able to detect damage to small fibers in patients with type 2 diabetes of any duration.

\section{Abbreviations \\ ADA: American Diabetes Association; ALAD: Latin American Diabetes Association; ANA: American Academy of Neurology; DPN: Diabetic peripheral neuropathy; ENSANUT: National Probabilistic Health Nutrition Survey; ESC: Electrochemical skin conductance; MNSI B: Part B of The Michigan Neuropathy Screening Instrument; MNSI: The Michigan Neuropathy Screening Instrument; NIS-LL: Neuropathy impairment score lower limb; UENS: Utah Early Neuropathy Score}

\section{Acknowledgements}

We thank Clinic detection and advanced diagnostic facilities for the recruitment of the sample used in this study.

\section{Funding}

Not applicable.

\section{Availability of data and materials}

The datasets used and/or analyzed during the current study are available from the corresponding author on reasonable request.

\section{Authors' contributions}

ACR: Coordinator, reviewer and clinical neurologist who carried out the clinical and SUDOSCAN studies. She also contributed with the design of the 
study, recruitment of patients and analysis and interpretation of the data. JAHD: Clinical Neurologist who recruited patients under the inclusion criteria and collected the data. MAMA: Endocrinologist in charge of the Diabetes clinic that identified a group of patients under the inclusion criteria and collected data. MMRU: Chemist who performed the necessary laboratory studies for the characterization of patients and contributed with the data analysis. ACN: Internist physician who collaborate in the clinical management of patients during the study and contributed with the data analysis interpretation. All authors have read and approved the manuscript.

\section{Ethics approval and consent to participate}

This study was approved by: Comité de Investigación y Ética en Investigación en Salud 3601 HOSPITAL DE ESPECIALIDADES DR. BERNARDO SEPULVEDA GUTIERREZ, CENTRO MEDICO NACIONAL SIGLO XXI. Number of the approval report for the execution R-2015-3601-51.

All participants provided their informed written consent participation.

\section{Consent for publication}

Not applicable

\section{Competing interests}

The authors declare that they have no competing interests.

\section{Publisher's Note}

Springer Nature remains neutral with regard to jurisdictional claims in published maps and institutional affiliations.

\section{Author details}

${ }^{1}$ Centro Médico Nacional Siglo XXI, Instituto Mexicano del Seguro Social (IMSS), Av. Cuauhtemoc 330, 06720 Mexico City, Mexico. ${ }^{2}$ Mexican Social Security Institute, Mexico City, Mexico. ${ }^{3}$ National Mexican Social Security Institute, Mexico City, Mexico.

\section{Received: 13 December 2017 Accepted: 13 May 2019}

\section{Published online: 31 May 2019}

\section{References}

1. Wild S, Roglic G, Green A, et al. Global prevalence of diabetes: estimates for the year 2000 and projections for 2030. Diabetes Care. 2004;27:1047-53.

2. International Diabetes Federation. IDF Diabetes Atlas, 6th edn. International Diabetes Federation; 2013.

3. Romero-Martínez M, Shamah-Levy T, Franco-Núñez A, Villalpando S, CuevasNasu L, Gutiérrez JP, National Health RDJA. Nutrition survey: design and coverage. Salud Publica Mex. 2013;55(suppl 2):S332-40

4. Arredondo A, De Icaza E. The cost of diabetes in Latin America: evidence from Mexico. Value Health. 2011;14(5Suppl 1):S85-8. https://doi.org/10.1016/ j.jval.2011.05.022

5. Boulton AJM. Management of Diabetic Peripheral Neuropathy. Clin Diabetes. 2005;23(1):9-15.

6. Sobhani S, Asayesh H, Sharifi F, Djalalinia S, Baradaran HR, Arzaghi SM Mansourian M, Rezapoor A, Ansari H, Masoud MP, Qorbani M. Prevalence of diabetic peripheral neuropathy in Iran: a systematic review and metaanalysis. J Diabetes Metab Disord. 2014;13:97. Published online 2014 Oct 15. https://doi.org/10.1186/s40200-014-0097-y.

7. Said G. Diabetic neuropathy-a review. Nat Clin Pract Neurol. 2007;3:331-40

8. Duby JJ, Campbell RK, Setter SM, White JR, Rasmussen KA. Diabetic neuropathy: an intensive review. Am J Health Syst Pharm. 2004;61(2):160-76.

9. Ribeiro de Souza L, et al. Meta-Analyses and Meta-Regression Of The Prevalence Of Diabetic Peripheral Neuropathy Among Patients With Type 2 Diabetes Mellitus. Int Arch Med, [S.I], 2016;9(65). ISSN 1755-7682.

10. American Diabetes Association. Diagnosis and classification of diabetes mellitus. Diabetes Care. 2010;33(Supplement 1):S62-9 doi.org/102337/DC 10-S062.

11. Tesfaye S, Boulton AJ, Dyck PJ, et al. Diabetic neuropathies: update on definition, diagnostic criteria, estimation of severity and treatments. Diabetes Care. 2010;33:2285-93.

12. Low PA. Evaluation of sudomotor function. Clin Neurophysiol. 2004;115: 1506-1.

13. Vinik Al, Maser RE, Mitchell BD, et al. Diabetic autonomic neuropathy. Diabetes Care. 2003;26(5):1553-79.
14. Pop-Busui R. Cardiac autonomic neuropathy in diabetes: a clinical perspective. Diabetes Care. 2010;33(2):434-41.

15. Moghtaderi A, Bakhshipour A, Rashidi H. Validation of Michigan neuropathy screening instrument for diabetic peripheral neuropathy. Clin Neurol Neurosurg. 2006;108(5):477-81.

16. Gibbons $\mathrm{CH}$, Cheshire WP, Fife TD. Autonomic Testing. Am Acad Neurol. 2015; $1-8$.

17. Escaño-Polanco FM, Odriozola A, Davidson J, Pedroza H, Fuente G, Márquez G, Braver JD, Pérez-Monteverde A, Litwak L, Olimpo Mendivil C, Rolím LC, Schmid H. Consenso de expertos para el manejo de la neuropatía diabética. Rev ALAD. 2016:6:121-50.

18. Casellini CM, Parson HK, Richardon MS, et al. Sudoscan, a noninvasive tool for detecting diabetic small fiber neuropathy and autonomic dysfunction. Diabetes Technol Ther. 2013;15(11):948-53.

19. Bordier L, Dolz M, Monteiro L, et al. Accuracy of a rapid and non-invasive method for the Assesment of small Fiber neuropathy based on measurement of electrochemical skin Conductances. Front Endocrinol (Laussane). 2016;7:18.

20. Yajnik CS, Kantikar W, Pande S \& al. Quick and Simple Evaluation of Sudomotor Function for Screening of Diabetic Neuropathy. ISRN.2012;2012: 103714. doi: https://doi.org/10.5402/2012/103714.

21. Smith $A G$, Lessard M, Reyna $S$, et al. The diagnostic utility of Sudoscan for distal symmetric peripheral neuropthy. J Diabetes Complicat. 2014;28(4):511-6.

22. Freedman $\mathrm{Bl}$, Bowden DW, Smith SC, et al. Relationships between electrochemical skin conductance and kidney disease in type 2 diabetes. J Diabetes Complicat. 2014;20(1):56-60.

23. Eranki VG, Santosh R, Rajitha $K$, et al. Sudomotor function assessment as a screening tool for microvascular complications in type 2 diabetes. Diabetes Res Clin Pract. 2013;101(3):e11-3.

24. Raisanen A, Eklund J, Calvet JH, et al. Sudomotor function as a tool for cardiorespiratory fitness level evaluation: comparison with maximal exercise capacity. Int J Environ Res Public Health. 2014;11:5839-48.

25. Selvarajah D, Cash T, Davies J, et al. SUDOSCAN: a simple, rapid, and objective method with potential for screening for diabetic peripheral neuropathy. PLoS One. 2015;10(10):e0138224.

26. $\{$ R Core Team\}. A Languaje and Enviroment for Statistical Computing.2014 http/www.R-project.org/

27. Smith AG, Russell J, Feldman EL, et al. Lifestyle intervention for pre-diabetic neuropathy. Diabetes Care. 2006;29(6):1294-9.

28. Gibbons $\mathrm{CH}$, Freeman R, et al. Diabetic neuropathy: a cross-sectional study of the relationships among tests of neurophysiology. Diabetes Care. 2010; 33(12):2629-34.

29. Lefaucheur JP, Wahab A, Plante-Bordeneuve V, et al. Diagnosis of small fiber neuropathy: a comparative study of five neurophysiological tests. Neurophysiol Clin. 2015;45(6):445-55.

Ready to submit your research? Choose BMC and benefit from

- fast, convenient online submission

- thorough peer review by experienced researchers in your field

- rapid publication on acceptance

- support for research data, including large and complex data types

- gold Open Access which fosters wider collaboration and increased citations

- maximum visibility for your research: over $100 \mathrm{M}$ website views per year

At BMC, research is always in progress.

Learn more biomedcentral.com/submission 